RESEARCH ARTICLE

\title{
Identification of stress tolerant rhizobial strains inhabiting Gliricidia sepium in Polonnaruwa district, Sri Lanka
}

\section{S.M.N.S. Samarakoon and S. Rajapakse*}

Department of Molecular Biology and Biotechnology, Faculty of Science, University of Peradeniya, Peradeniya, Sri Lanka.

Received: 02/08/2019 ; Accepted: 26/02/2020

\begin{abstract}
Rhizobia are well-reputed biological nitrogen fixing organisms due to their proficiency in symbiotic root nodule formation with leguminous plants. Gliricidia sepium is a widely distributed legume which hosts a wide range of rhizobia. Few studies have been carried out to identify the stress tolerant rhizobial populations inhabiting G. sepium in Sri Lanka. This study was focused on the characterization and identification of stress tolerant rhizobial strains residing in the root nodules of $G$. sepium growing in seven selected locations of Polonnaruwa district, Sri Lanka. Isolated rhizobial strains were separately subjected to stress conditions ( $\mathrm{pH}$, temperature, salinity, and drought) and to a combination of given stress conditions. Most of the strains were tolerant to $25-45{ }^{\circ} \mathrm{C}$ temperature range, extreme drought conditions and $1.5 \%$ and $2.0 \%$ salinity levels. However all the strains were adversely affected by acidic $\mathrm{pH}$. Among the fifteen strains that were selected from the statistical analysis, fourteen displayed higher survival capacity when the combinations of physiological conditions were applied. There was great genetic diversity within these isolates and they belonged to 10 clusters. Cross inoculation of these isolated stress tolerant strains into crop legumes can be used as an ideal alternative for chemical nitrogen fertilizers.
\end{abstract}

Keywords: ERIC 1R, ERIC 2R, pH tolerance, Biological Nitrogen Fixation, Combination of physiological conditions.

\section{INTRODUCTION}

Biological Nitrogen Fixation (BNF) is the conversion of atmospheric dinitrogen to available forms such as $\mathrm{NH}_{4}$. In the symbiotic association between nitrogen-fixing bacteria and the leguminous plants, the legumes transfer their photosynthetic carbon into the nodules to generate energy through microbial respiration under low oxygen concentrations for the nitrogenase enzyme catalyzed reduction of dinitrogen to ammonia which is incorporated as amino acids (Franche et al., 2009). Usually, BNF fulfills the major nitrogen requirement of crop legumes, and the excess amount is released to the soil (Peoples and Craswell, 1992). Thus, rhizobia can contribute to an economically attractive and ecologically beneficial agricultural system through BNF.

G. sepium, which belongs to the family Fabaceae is a multipurpose tree legume that is widely distributed throughout the world, including Sri Lanka. Due to its high biomass production and extensive range of soil and climatic adaptation abilities, G. sepium is cultivated as the second most crucial multipurpose tree legume after Leucaena leucocephala (Jayasundara et al., 1997). In Sri Lanka, G. sepium is cultivated in coconut fields to improve soil fertility and enhance the productivity of coconut cultivations by facilitating the fixation of atmospheric nitrogen around $64 \%$ in field conditions (Liyanage et al., 1994; Liyanage et al., 1988). Moreover, G. sepium is used as a nitrogen fertilizer, animal forage, fuelwood, green manure, shade trees for plantation crops, and as a soil stabilizer (Jayasundara et al., 1997). In addition to tea, rubber, and coconut, the Sri Lankan government has nominated $G$. sepium as the $4^{\text {th }}$ major plantation crop in Sri Lanka for the generation of dendro power.

G. sepium is widely distributed in the Polonnaruwa district, due to its soil fertility enhancement, soil erosion prevention, and soil rehabilitation capacity in the poorquality soil (Gunathilake et al., 2005). According to Udagedara and Sugirtharan, (2018), the atmospheric temperature in Polonnaruwa district exceeds $30{ }^{\circ} \mathrm{C}\left(30^{\circ} \mathrm{C}\right.$ $33^{\circ} \mathrm{C}$ ) throughout the year and it leads to a high evaporation rate. Although the annual rainfall in Polonnaruwa district is $1180-1800 \mathrm{~mm}, 34.9 \%$ of agro-based activities such as paddy cultivation, homesteads, and croplands are the primary sources of income. Moreover, people abundantly cultivate crop legumes such as cowpea, green gram, black gram, groundnut, and beans for over 120 years and rhizobia had been used as a biofertilizer in agriculture in Sri Lanka perhaps during the past four decades (Kulasooriya et al., 2017). As a general practice, G. sepium is purposely cultivated along agricultural lands to increase soil nitrogen fertility through BNF (Ulluwishewa, 1993).

Rhizobia belong to the classes alpha-proteobacteria and beta-proteobacteria, based on the information obtained from $16 S$ rRNA sequence analyzing (Somasegaran and Hoben, 2012; Sawada et al., 2003). Furthermore, rhizobia can be classified into six genera; Rhizobium, Bradyrhizobium, Sinorhizobium, Mesorhizobium, Azorhizobium, and Allorrhizobium (Brockwell et al., 2005). According to the 
host range factor, Rhizobium is further classified into six species; Rhizobium leguminosarum, R. trifolii, R. phaseoli, $R$. meliloti, $R$. japonicum, and R. lupin (Peter et al., 1996). However, the environmental conditions are strongly related to the physiological state of host legumes such as extreme salinity and temperature, unfavorable soil $\mathrm{pH}$, drought, nutrient deficiency, mineral toxicity, and plant diseases affect the rhizobial growth and efficiency of nitrogen fixation in legumes (Brockwell et al., 1995). Among the six genera, Rhizobium and Bradyrhizobium have a higher tolerance for severe conditions and most of them can be found within the legume-based crops. Although the optimum temperature of most of the in vitro cultured rhizobia is $28-31{ }^{\circ} \mathrm{C}$; some strains like $R$. leguminosarum can survive extreme temperatures up to $35-40{ }^{\circ} \mathrm{C}$ by forming an effective symbiotic association with the host legume (Graham, 1992; Zahran, 2001). Even though the optimum $\mathrm{pH}$ range found in growing culture is 6.0-7.0, $R$. trifolii even can tolerate high acidic condition such as pH 4.5 (Martinez-Romero et al., 1991). Specific colony morphologies such as round shaped, domed, smooth margined, gummy and soft, glistening and milky to thin and translucent features can be used to isolate the rhizobia in stable physiological states (Somasegaran and Hoben, 2012).

Research studies on the symbiotic nitrogen-fixing efficiency of legume plants in both controlled environmental conditions and field conditions had been conducted in many countries including Sri Lanka . Only few studies have focused on the physiological characterization and genetic diversity of stress tolerant rhizobial strains of certain legume crops and their wild relatives (Hettiarachchi et al., 2013a and 2013b), but these research have not studied about G. sepium. Thus, the present study was mainly focused on isolating rhizobia from $G$. sepium in selected locations of Polonnaruwa district, Sri Lanka and physiologically characterize them under different stress conditions such as $\mathrm{pH}$, salinity, drought, and temperature and to determine the genetic diversity of stress tolerant strains by Enterobacterial Repetitive Intergenic Consensus (ERIC) profiling. According to Hettiarachchi, (2015), crop lrgumes cross inoculated by single strain and multi starin inoculants have shown great yield in each trial compared to the chemical nitrogen fertilizer application. Thus, identified stress tolerant rhizobial strains will clearly be a great alternative to commercially used chemical nitrogen fertilizers like urea and further exploiting these strains by cross inoculating to crop legumes can lead to establishing a sustainable agricultural system in the dry zone.

\section{MATERIALS AND METHODS}

\section{Sample collection}

Root nodules of G. sepium were collected from randomly selected seven locations (Moragaswewa [Mw], Bakamuna [B], Jayanthipura [J], Aralaganwila [A], Monarathanna [Mn], Sinhapura [Si], and Medirigiriya [Mg]) in the Polonnaruwa district, Sri Lanka. Five nodules from each location were selected from the collected samples.

\section{Preparation of culture medium}

For the preparation of $1 / 2$ Lupine Agar (1/2 LA) medium, $5 \mathrm{~g}$ of mannitol, $5 \mathrm{~g}$ of D-glucose and $1.25 \mathrm{~g}$ yeast extract were weighed using a micro-scale. The components were dissolved in $100 \mathrm{ml}$ of deionized distilled water, and 0.8 $\mathrm{g}$ of $\mathrm{MgSO}_{4}, 0.2 \mathrm{~g}$ of $\mathrm{NaCl}$ and $0.2 \mathrm{~g}$ of $\mathrm{CaCl}_{2} \cdot 2 \mathrm{H}_{2} \mathrm{O}$ were dissolved in another $100 \mathrm{ml}$ of deionized distilled water. Both solutions were mixed, and the precipitation was checked. After that, $10 \mathrm{ml}$ of $\mathrm{KH}_{2} \mathrm{PO}_{4}, 10 \mathrm{ml}$ of $\mathrm{K}_{2} \mathrm{HPO}_{4}$, $5 \mathrm{ml}$ of $\mathrm{Fe}_{2}\left(\mathrm{SO}_{4}\right)_{3}$ and $1 \mathrm{ml}$ of trace elements were added to the mixture, if there is no precipitation found. Then 10 $\mathrm{ml}$ of Congo red solution $(0.25 \mathrm{~g} / 100 \mathrm{ml})$ was added as the indicator, and the $\mathrm{pH}$ was adjusted to 6.8. The volume of the final solution was adjusted to $1000 \mathrm{ml}$, and $18 \mathrm{~g}$ of agar was added to the final mixture. After the preparation, the medium was covered by cotton wool and aluminum foil and autoclaved at $15 \mathrm{lbs}$. pressure $\left(121^{\circ} \mathrm{C}\right)$ for 15 minutes.

\section{Isolation of rhizobia from root nodules}

The roots were washed carefully to remove soil particles using running tap water, and undamaged five nodules from each location (total nodules 35 ) were selected. These nodules were surface sterilized under a laminar floor, by washing with $70 \%$ ethanol for 30 seconds followed by $3 \%$ (v/v) Sodium hypochlorite for 2 minutes and five times with sterilized distilled water. In applying the crush method, nodules were crushed using a blunt end of a sterilized toothpick and the nodule suspension was streaked on $1 / 2 \mathrm{LA}$ medium using the blunt end of the toothpick under sterile conditions. After culturing the selected 35 nodules, all the culture plates were sealed and labeled. Culture plates were incubated at room temperature for 4-5 days in dark conditions. After the incubation period, sub-culturing was done using colonies that have the typical morphology of Rhizobium sp. Successive sub-culturing was done for more than five times to obtain pure cultures, and Congo Red $1 / 2$ LA stock cultures were stored in the refrigerator.

\section{Characterization of the tolerance of Rhizobium for physiological conditions (pH, Drought, Salinity, and Temperature)}

The $1 / 2$ Lupine broth (1/2 LB) medium (without Congo red) having a range of $\mathrm{pH}$ from 3-9 was prepared for $\mathrm{pH}$ tolerance, Polyethylene glycol-8000 (PEG 8000) concentration as 0.1 $\%, 0.2 \%, 0.3 \%$, and $0.4 \%$ for drought tolerance and $\mathrm{NaCl}$ concentration as $0.1 \%, 1 \%, 1.5 \%, 2 \%, 2.5 \%$ and $3 \%$ for salinity tolerance. Then, $5 \mathrm{ml}$ of $1 / 2 \mathrm{LB}$ medium was added to each test tube including the control sample. All the test tubes were wrapped in aluminum foil and autoclaved. After that, samples were inoculated for each parameter separately using a loop full of isolated rhizobia excluding the control. Duplicate test tubes were set up per treatment. The samples for $\mathrm{pH}$ tolerance, drought tolerance, and salinity tolerance were incubated at room temperature while the samples for testing temperature tolerance were incubated at $25^{\circ} \mathrm{C}, 30$ ${ }^{\circ} \mathrm{C}, 35^{\circ} \mathrm{C}, 40{ }^{\circ} \mathrm{C}$, and $45^{\circ} \mathrm{C}$ separately for three days in dark condition. After the incubation period, the absorbance of all the cultures under different treatments was measured at $600 \mathrm{~nm}$ and $570 \mathrm{~nm}$ wavelengths respectively using a Spectrophotometer. This procedure was done in duplicate. 


\section{Characterization of the tolerance of rhizobial strains for a combination of different physiological conditions}

The rhizobial strains that have a tolerance to different stresses were selected. Four physiological parameters were selected according to the existing natural soil conditions in Polonnaruwa district. The selected strains were subjected to a combination of conditions such as $6.8 \mathrm{pH}, 0.4 \% \mathrm{PEG}$ concentration, $3.0 \%$ salinity level, and $40{ }^{\circ} \mathrm{C}$ temperature. All the treated samples were incubated for three days, and the absorbance was measured at $600 \mathrm{~nm}$ wavelength using a spectrophotometer.

\section{Genomic DNA extraction and ERIC-PCR fingerprinting}

The selected 15 rhizobial strains that have the tolerance to different stresses were cultured in $1 / 2$ LA medium and incubated in dark conditions for three days. After the incubation period, genomic DNA of 15 selected strains was extracted using the phenol/chloroform method. DNA fingerprinting was carried out using ERIC $1 R$ primer (5'ATGTAAGCTCCTGGGGAATCAC3') and ERIC $2 R$ primer (5'AAGTAAGTGACTGGGGTGAGCG3') (Versalovic et al., 1991) for the selected strains. The 15 $\mu \mathrm{l}$ PCR reaction mixture was prepared by adding $1 \mu \mathrm{l}$ of genomic DNA, $7.5 \mu$ of Go Taq green master mixture, 0.5 $\mu 1$ of primer $1 R, 0.5 \mu 1$ of primer $2 R$ and $5.5 \mu$ l of nucleasefree water. The PCR amplification was carried out by holding the reaction mixture at $94{ }^{\circ} \mathrm{C}$ for $5 \mathrm{~min}$ followed by 35 cycles at $90^{\circ} \mathrm{C}$ for $30 \mathrm{sec}, 46^{\circ} \mathrm{C}$ for $1 \mathrm{~min}$ and a final extension at $70{ }^{\circ} \mathrm{C}$ for $10 \mathrm{~min}$ in the thermal cycler (Takara Otsushiga, Japan). The amplified DNA fragments from the selected rhizobial strains were visualized using Agarose Gel electrophoresis in a 3.5\% agarose gel.

\section{Data analysis and representation}

The bar charts were prepared using Microsoft Office Excel to compare the absorbance values for all physiological conditions from all seven sites. The strains with higher growth under extreme conditions were selected by subjecting absorbance values to General Linear Model (GLM) procedure and LS means pdiff mean separation procedure using a statistical package, SAS 9.3.1 (SAS Institute, NC Cary, USA). A dendrogram was constructed for the selected 15 rhizobial strains that exhibited tolerance to adverse conditions by Complete Linkage, Euclidean Distance method using the software MINITAB 17.1.0.

\section{RESULTS}

\section{pH tolerance}

All 35 samples from the seven sites have a common growth pattern between 3 to $5 \mathrm{pH}$ range. All strains show poor growth at $\mathrm{pH} 3.0$ and 4.0 and better growth at $\mathrm{pH}$ 6.0 to 8.0 . When the $\mathrm{pH}$ is changed from 4.0 to 5.0 , the growth of most rhizobial strains increased drastically. At the alkaline $\mathrm{pH}$, strains MW-e, B-d, A-c, MN-e, and Si-e showed a higher tolerance compared to others. Although some strains tolerate alkaline $\mathrm{pH}$, isolates $\mathrm{MW}-\mathrm{b}, \mathrm{A}-\mathrm{c}, \mathrm{J}-\mathrm{c}$, J-d, A-e, MW-c, MN-c, MN-d, and Mg-d showed poor tolerance for $\mathrm{pH} 9.0$ (Figure 1).
Although MW-e strain had a high tolerance at alkaline $\mathrm{pH}$, the growth of the other strains in Moragaswewa site reduced with the increase of $\mathrm{pH}$. Moreover, MW-b and $\mathrm{MW}$-a strains show a relatively low growth rate at each $\mathrm{pH}$ level $(<0.6840$ mean absorbance value) (Figure 1A). Strain B-d of Bakamuna site has the highest growth rate at $\mathrm{pH}$ 5.0, 6.0 and 9.0. The B-d strain shows the highest fluctuation in growth rates at different $\mathrm{pH}$. (Figure 1B). Except for the acidic $\mathrm{pH}$, the $\mathrm{J}-\mathrm{a}, \mathrm{J}-\mathrm{b}$, and $\mathrm{J}$-e strains have survival ability at other $\mathrm{pH}$ levels than J-c and J-d (Figure 1C). In Aralaganiwila site, A-a and A-c rhizobial strains have high growth at $\mathrm{pH} 7.0$ and 8.0 (above 1.2000). When the $\mathrm{pH}$ gradually increases up to $\mathrm{pH} 9.0$, the growth of A-b strain decreases while the growth of A-d strain increases (Figure 1D). Although MN-b, MN-d, and MN-e show tolerance for $\mathrm{pH} 7.0$ and 8.0, only MN-e strain has tolerance at $\mathrm{pH}$ 9.0. However, MN-d shows highest tolerance $(>1.2000$ mean absorbance) at neutral $\mathrm{pH}$ than other strains in Monarathanna site. When the $\mathrm{pH}$ increases gradually from 7.0 to 9.0 , the tolerance of $\mathrm{MN}$-a strain is increased (Figure 1E). All strains in Sinhapura site, show exponential growth in 4.0-8.0 $\mathrm{pH}$ range. However, only $\mathrm{Si}$-e strain shows high growth at $\mathrm{pH} 9.0$ while the growth of other strains decreases drastically (Figure 1F). In Madirigiriya site, the $\mathrm{Mg}-\mathrm{b}$ and Mg-e strains show high growth at alkaline $\mathrm{pH}$ while showing less growth at acidic pH (Figure 1G).

\section{Drought tolerance}

A clear pattern of the growth cannot be observed in 35 rhizobial strains at different PEG concentration $(0.10 \%$ - $0.40 \%$ PEG). Because most of the strains exhibit more than 0.5000 of mean absorbance value and A-c strain has the highest growth at $0.20 \%$ PEG concentration. However, most of the rhizobial strains survive under high PEG concentration (Figure 2).

In Moragaswewa site, the MW-a strain shows the highest growth (0.9980 mean absorbance) at $0.4 \%$ PEG concentration (Figure 2A). Although the B-e strain shows great survival ability at the $4.0 \%$ drought level, the growth of other strains in Bakamuna site is decreased (Figure 2B). The J-c strain that isolated from Jayanthipura site shows the highest growth at high drought condition. The growth of all strains from Jayanthipura is moderately tolerant to high drought conditions except for the J-b strain (Figure 2C). In Aralaganwila site, all strains are capable of surviving at high drought conditions except for the A-a strain. The A-c strain exhibits the highest growth at $0.20 \%$ PEG concentration (Figure 2D). All strains in Monarathanna site have a moderate ability to survive at each drought level $(>0.7000)$. At the $0.40 \%$ concentration, $\mathrm{MN}-\mathrm{a}$ and $\mathrm{MN}-\mathrm{e}$ strains show relatively higher growth than other strains (Figure 2E). As the drought stress rises, only Si-c strain shows a gradual increase in growth while the growth of all the other strains from Sinhapura site decreases when the PEG concentration changes from $0.3 \%$ to $0.4 \%$. In Madirigiriya site, the growth of Mg-c strain is exponentially decreased with the increase in drought. But Mg-e strain has great survival ability even at high drought level (Figure 2G). 


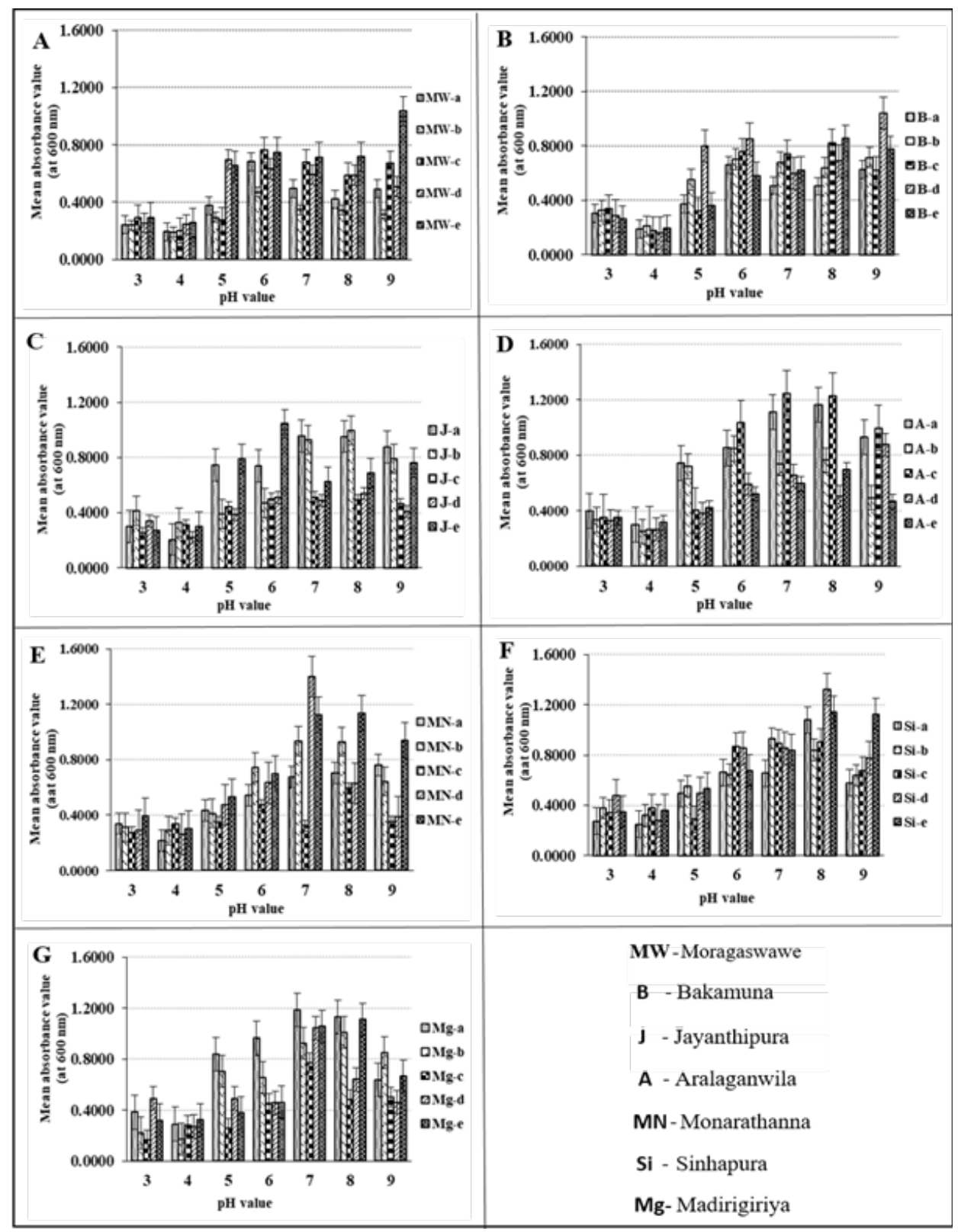

*Error bar $(+\mathrm{T} /-\perp)$ indicates the standard error of the sample

Figure 1: Growth of isolated rhizobial strains from 7 sites at different $\mathrm{pH}$ values. Five strains from each site grow in the 3.0-9.0 $\mathrm{pH}$ range. The optical absorbance measured at $600 \mathrm{~nm}$ to determine growth at $600 \mathrm{~nm}$. All rhizobial strains except Moragaswewa and Sinhapura strains show a radical increase in their growth when the $\mathrm{pH}$ changed from 4.0 to 5.0. All 35 strains exhibit greater survival under alkaline $\mathrm{pH}$ conditions than acidic $\mathrm{pH}$ conditions because the strains in seven sampling sites show high growth at alkaline $\mathrm{pH}$.

\section{Salinity tolerance}

A considerable growth of 35 isolates can be observed at different concentrations of $\mathrm{NaCl}(0.1 \%, 1.0 \%, 1.5 \%$, $2.0 \%, 2.5 \%$ and $3.0 \%$ ) which is used to induce the salt stress in culture medium. Although most strains show high growth at $1.0 \%$ or $1.5 \%$ concentration, the A-b and B-c strains show a higher growth at $1.5 \%$ than the other strains. Tolerance of most strains is relatively low at high salinity levels. However, there is no visible pattern of growth in response to different salt stresses (Figure 3).

MW-c strain shows relatively high tolerance at the extreme salt level than others. However, the growth of all strains gradually reduces with the change of $\mathrm{NaCl}$ concentration from $1.5 \%$ to $3.0 \%$ (Figure $3 \mathrm{~A}$ ). The B-c strain shows high growth at $1.5 \%$ concentration level while the B-d strain shows relatively high growth at 3.0 $\%$ concentration. When salt stress is increased, the growth of all the strains of Bakamuna site is reduced except for B-d strain (Figure 3B). In Jayanthipura site, all strains show moderate tolerance at the highest salt level except $\mathrm{J}-\mathrm{c}$ strain. Moreover, they have the highest survival ability at $1.5 \% \mathrm{NaCl}$ level (Figure 3C). Although the A-b strain exhibited the highest growth at $1.5 \%$, the growth is reduced with the increase of salt stress. Relatively, the growth of all the strains sensitive to high salt stress (Figure 3D). In Monarathanna site, MN-c strain shows the highest growth at $3.0 \%$ salt stress level. When the $\mathrm{NaCl}$ concentration 


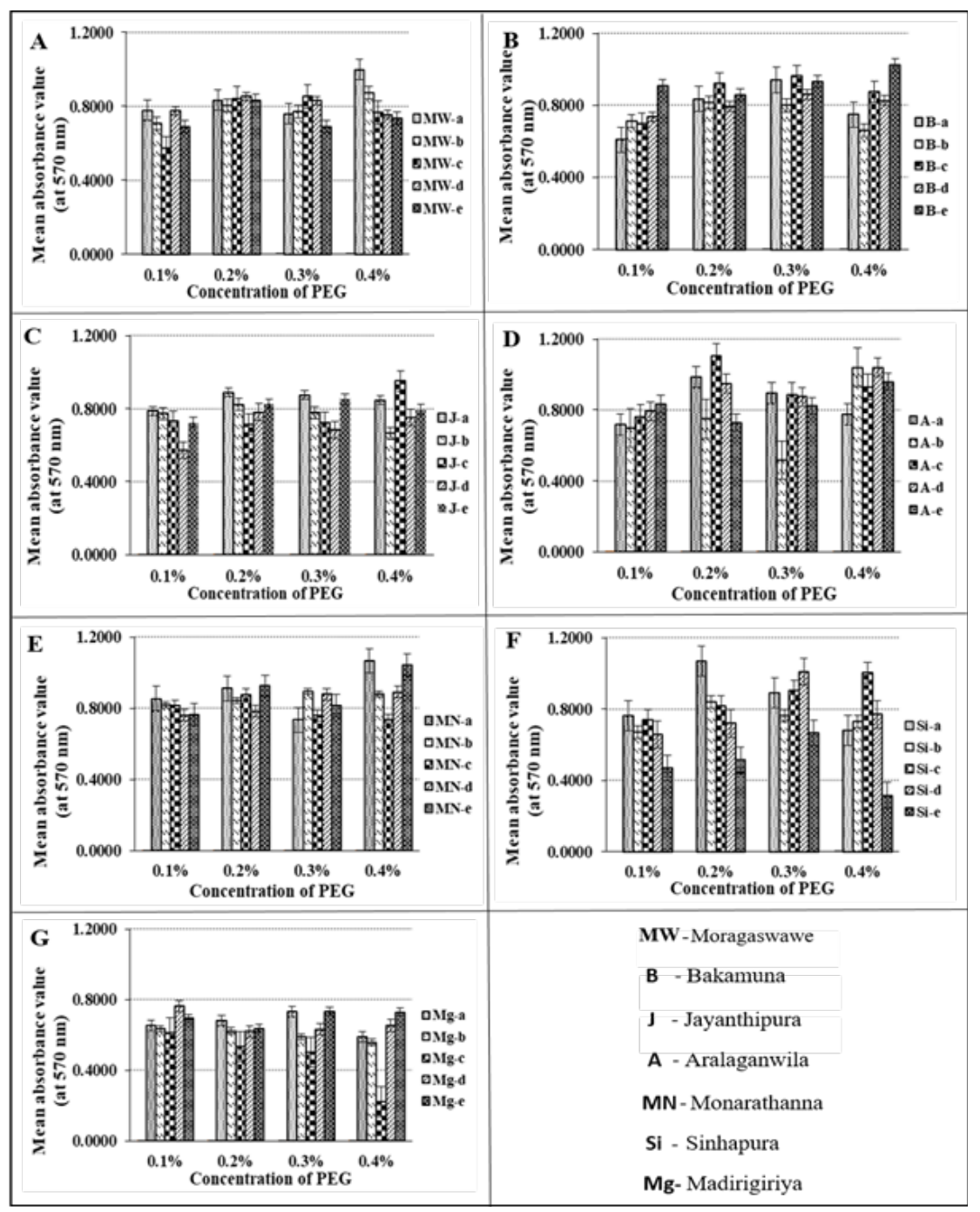

*Error bar $(+\mathrm{T} /-\perp)$ indicates the standard error of the sample.

Figure 2: The growth of isolated Rhizobium strains from 7 sites at different drought levels. The Polyethylene Glycol (PEG) use in different concentrations $(0.1 \%, 0.2 \%, 0.3 \%$, and $0.4 \%)$ to induced drought stress in the culture medium. The optical absorbance measured at $570 \mathrm{~nm}$ to determine the growth. The growth of most samples in 7 sites except for Si-e and Mg-c show tolerance to high drought stress. A-b, A-d, MN-a, MN-e, and Si-c Rhizobium strains show the highest growth with more than 1.0000 mean absorbance value at $0.40 \%$ concentration. However, the visible pattern of growth cannot be observed in response to increases in PEG concentration from $0.10 \%$ to $0.40 \%$.

changes from $1.0 \%$ to $3.0 \%$, the growth of some strains is exponentially reduced (Figure $3 \mathrm{E}$ ). The growth of all strains in Sinhapura site increases in the range of $2.0 \%$ to $3.0 \%$. However, Si-e strain shows greate survival ability at low salinity levels (Figure 3F). Mg-b and Mg-e strains show slightly similar growth at $3.0 \%$ concentration. But, the growth of Mg-a, Mg-c, and Mg-d strains are reduced when the $\mathrm{NaCl}$ concentration changes from $1.5 \%$ to $3.0 \%$ (Figure 3G).

\section{Temperature tolerance}

The temperature tolerance is evaluated by incubating isolated rhizobial strains cultured in $1 / 2 \mathrm{LB}$ at different temperatures $\left(25^{\circ} \mathrm{C}, 30^{\circ} \mathrm{C}, 35^{\circ} \mathrm{C}, 40^{\circ} \mathrm{C}\right.$, and $\left.45^{\circ} \mathrm{C}\right)$. Most strains in each site show high growth at $25^{\circ} \mathrm{C}$ and $30^{\circ} \mathrm{C}$, but few strains like MW-a, MW-b, and A-c show the highest growth at $45^{\circ} \mathrm{C}$. There is no any clear observable pattern of growth since, the strains in Moragaswewa, Sinhapura, Monarathanna, and Medirigiriya sites show less growth at high temperatures while strains in Aralaganwila and Jayanthipura sites show little increase in growth at high temperature than at low temperature (Figure 4).

With increasing temperature, the growth of MW-d strain decreases exponentially, while the growth of MW-c and MW-e strains increased. However, MW-a and MW-b strains had a greater survival ability at high temperatures than other strains in Moragaswewa site (Figure 4A). In Bakamuna site, B-d strain shows the highest growth in 35 ${ }^{\circ} \mathrm{C}$ to $45{ }^{\circ} \mathrm{C}$ temperature range while the survival ability of the other four strains decrease when the temperature is increased (Figure 4B). Among the well-grown J-c, J-d and J-e strains, J-e strain has the highest tolerance at high temperatures than others. Moreover, the growth of J-a and J-b strains decrease at high temperature (Figure 4C). 


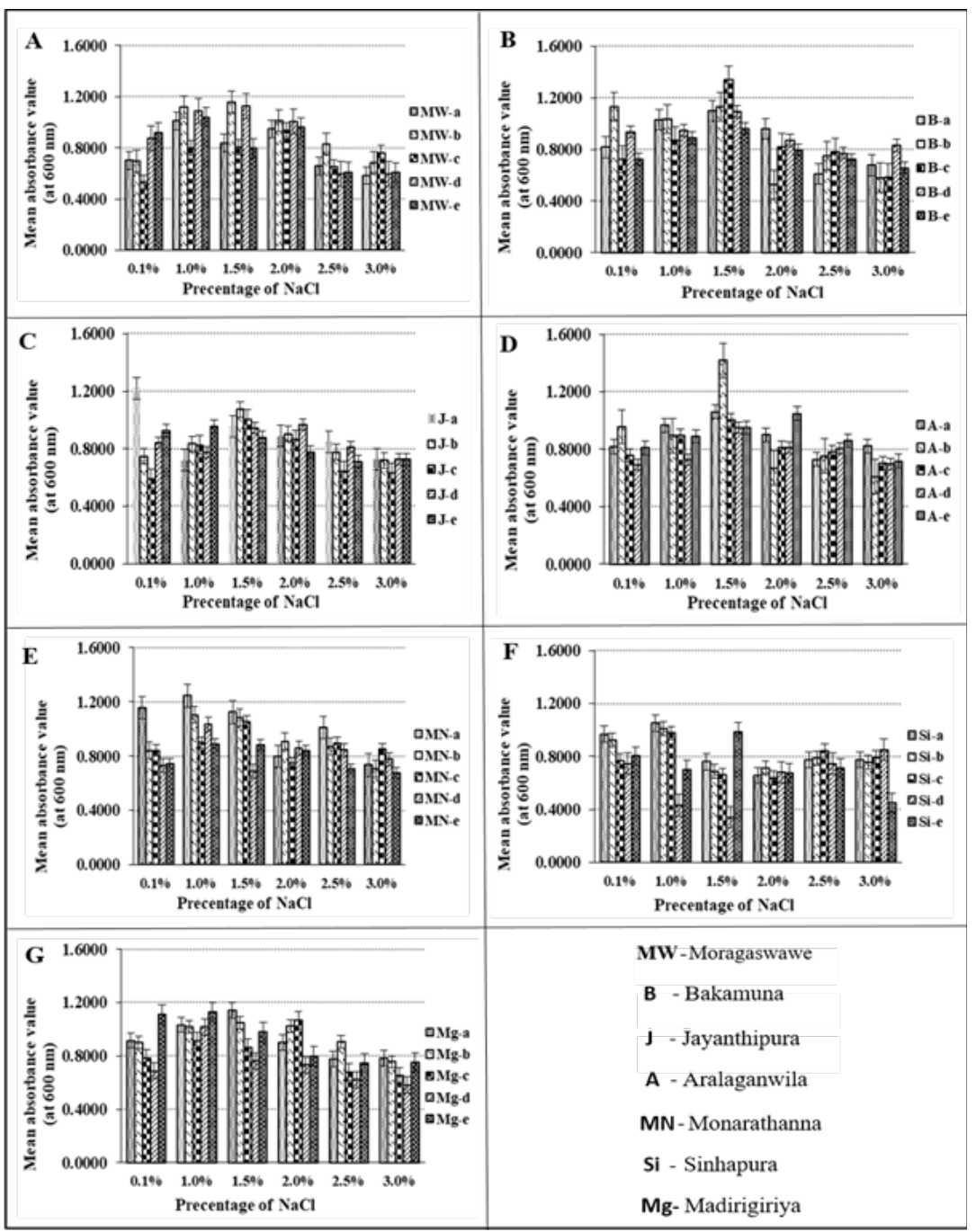

*Error bar $(+\mathrm{T} /-\perp)$ indicates the standard error of the sample.

Figure 3: The growth of isolated Rhizobium strains from 7 sites at different salinity levels. $\mathrm{NaCl}$ was used at different concentrations $(0.1 \%, 1.0 \%, 1.5 \%, 2.0 \%, 2.5 \%$ and $0.4 \%)$ to induce salt stress in the culture medium. The optical absorbance determined the growth at $600 \mathrm{~nm}$. The growth of strains from all the 7 sites decreased at $2.5 \%$ and $3.0 \%$ while higher growth was shown at $1.0 \%$ or $1.5 \%$ concentration level. At high salinity level, A-b, and B-c rhizobial strains showed the highest growth. However, there is no visible pattern of growth in response to salt stresses.

The growth of A-a, A-c, and A-d strains increase while the A-b and A-e strains show less growth within $35^{\circ} \mathrm{C}$ to $45^{\circ} \mathrm{C}$ temperature range. However, A-c strain shows the highest tolerance even at $45^{\circ} \mathrm{C}$ (Figure 4D). The growth of $\mathrm{MN}-\mathrm{a}$ strain exhibits a higher tolerance at $40{ }^{\circ} \mathrm{C}$ and $45^{\circ} \mathrm{C}$ temperatures than other strains. The $\mathrm{MN}-\mathrm{d}$ strain maintains its growth in a relatively constant rate within the $35^{\circ} \mathrm{C}-45$ ${ }^{\circ} \mathrm{C}$ temperature range while showing a high growth at 25 ${ }^{\circ} \mathrm{C}$ (Figure 4E). When increasing the temperature from 35 ${ }^{\circ} \mathrm{C}$ to $45^{\circ} \mathrm{C}$, the growth of Si-a, Si-c, Si-d and Si-e strains in Sinhapura site is reduced. However, Si-b strain shows higher survival ability at $45^{\circ} \mathrm{C}$ level (Figure 4F). When temperature change from $30^{\circ} \mathrm{C}$ to $45^{\circ} \mathrm{C}$, the overall growth of strains in Madirigiriya site is reduced. However, Mg-e strain shows a higher growth rate at $45^{\circ} \mathrm{C}$ than other strains (Figure 4G).

\section{Tolerance for a combination of physiological} conditions.

The 15 rhizobial strains that had a higher tolerance to individual physiological conditions exhibit survival ability under laboratory conditions. Instead of extreme temperature and extream $\mathrm{pH}$ like $45^{\circ} \mathrm{C}$ and 9.0 respectively, combination experiment conducts using the conditions which exist in the soil of Polonnaruwa district. In the combination conditions, MW-a strain shows less growth than in the individual physiological conditions. And Sib, Si-c, and Mg-e strains show the highest growth at combination condition. However, 14 strains show great tolerance to adverse physiological conditions except for MW-a strain (Figure 5).

\section{Genetic diversity and correlation between selected Rhizobium strains}

When visualizing the PCR amplicons amplified using ERIC primers of the selected 15 Rhizobium strains using gel electrophoresis, a highly polymorphic ERIC-PCR profile was obtained. Here, some bands are common and prominent in each strain while other bands are specific for a strain. And 15 strains have two dominant bands with close band length. 


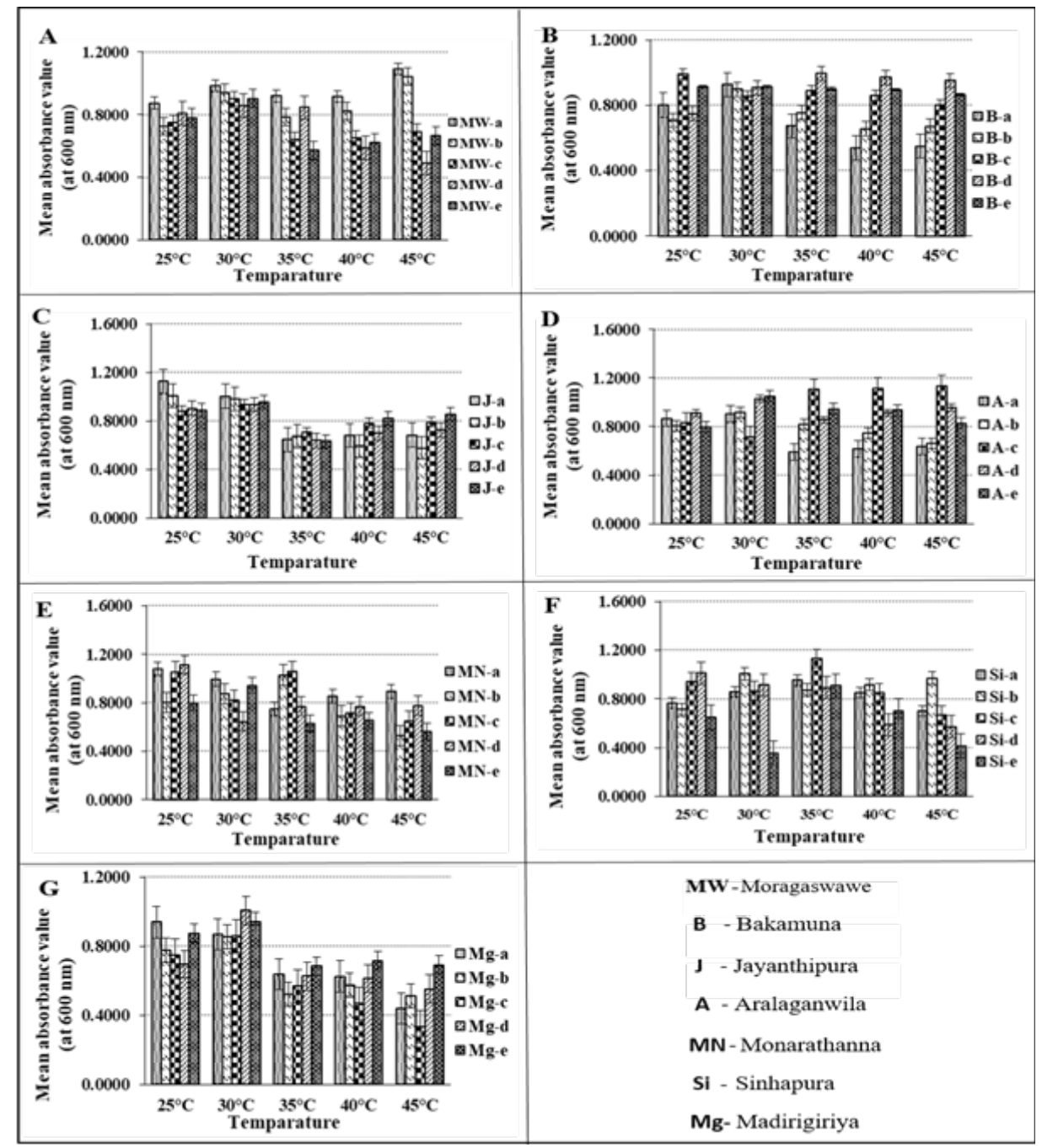

*Error bar $(+\mathrm{T} /-\perp)$ indicates the standard error of the sample.

Figure 4: The growth of isolated Rhizobium strains from 7 sites at different temperature levels. The growth medium incubates at different temperatures $\left(25^{\circ} \mathrm{C}, 30^{\circ} \mathrm{C}, 35^{\circ} \mathrm{C}, 40{ }^{\circ} \mathrm{C}\right.$, and $\left.45^{\circ} \mathrm{C}\right)$ to induce the stress and the optical absorbance measured at $600 \mathrm{~nm}$ to determine the growth. Most strains show a higher growth at $25^{\circ} \mathrm{C}$ and $30^{\circ} \mathrm{C}$ temperature. However, MW-a, MW-b, and A-c strains show the highest growth at $45^{\circ} \mathrm{C}$. However, there is no any noticeable pattern of growth in response to the temperature difference since the growth of few strains such as A-C, J-e, and Si-b increase while the growth of other strains reduces with the changing of temperature.

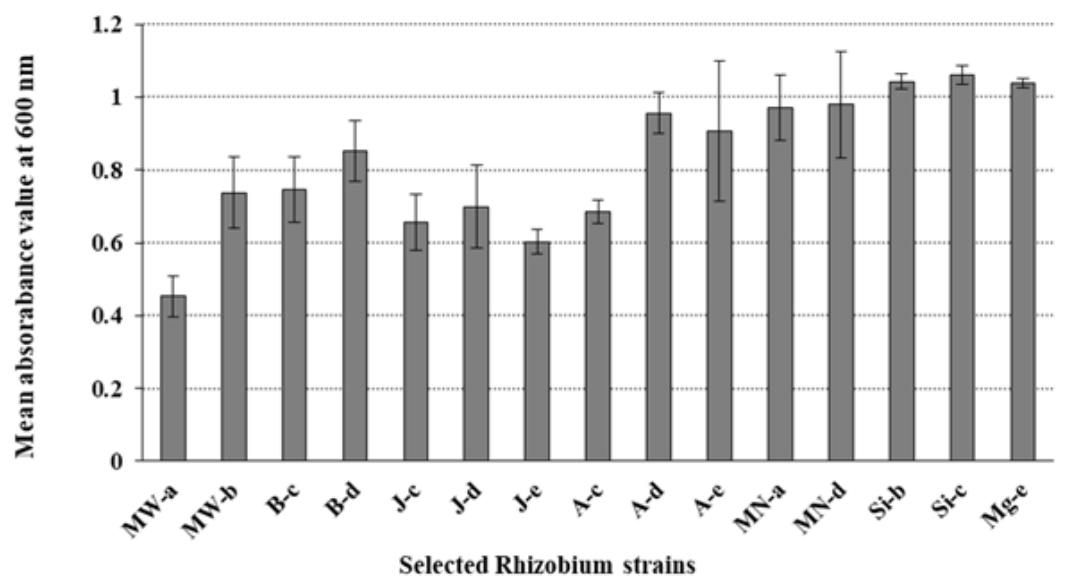

*Error bar $(+\mathrm{T} /-\perp)$ indicates the standard error of the sample

Figure 5: Growth of 15 selected Rhizobium strains under a combination of different physiological conditions. These strains were cultured in a medium with $3.0 \% \mathrm{NaCl}, 0.4 \% \mathrm{PEG}$ and $\mathrm{pH} 6.8$ and incubated at $40{ }^{\circ} \mathrm{C}$. The growth was evaluated by measuring the absorbance at $600 \mathrm{~nm}$. The MW-a strain showed less growth while Si-c, Si-b and Mg-e strains showed higher growth under these combined conditions. 
MW-a and MW-b strains show specific banding pattern than other strains. Moreover, Mg-e strain shows a different pattern while j-c, J-b and B-c strains have common banding pattern (Figure 6). Based on the ERIC profile of selected 15 rhizobial strains, the dendrogram is constructed to assess the genetic diversification and the relationship between strains. The B-c, J-c, and J-d strains cluster together at $75 \%$ molecular similarity coefficient. The 15 rhizobial strains fall into 10 clusters at $65 \%$ molecular similarity coefficient. At $50 \%$ molecular similarity coefficient, the B-d strain cluster together with B-c, J-c, J-d, and J-e strains. And also, MN-a and MN-d strains belong to one cluster and $\mathrm{A}-\mathrm{e}, \mathrm{Mg}-\mathrm{e}, \mathrm{Si}-\mathrm{b}$, and $\mathrm{Si}-\mathrm{c}$ belong to another cluster at
$50 \%$ molecular similarity coefficient level. The A-c and A-d strains belong to different clusters at $40 \%$ and 38.7 $\%$ molecular similarity coefficient respectively. The MW-a and MW-b strains cluster together at $44 \%$ molecular similarity coefficient as an outgroup. (Figure 7).

\section{DISCUSSION}

The isolated rhizobial strains that inhabit the root nodules of G. sepium in randomly selected seven locations (Moragaswewa, Bakamuna, Jayanthipura, Aralaganwila, Monarathanna, Sinhapura, and Madirigiriya) of Polonnaruwa district showed a great survival ability for adverse physiological conditions. G. sepium is widely

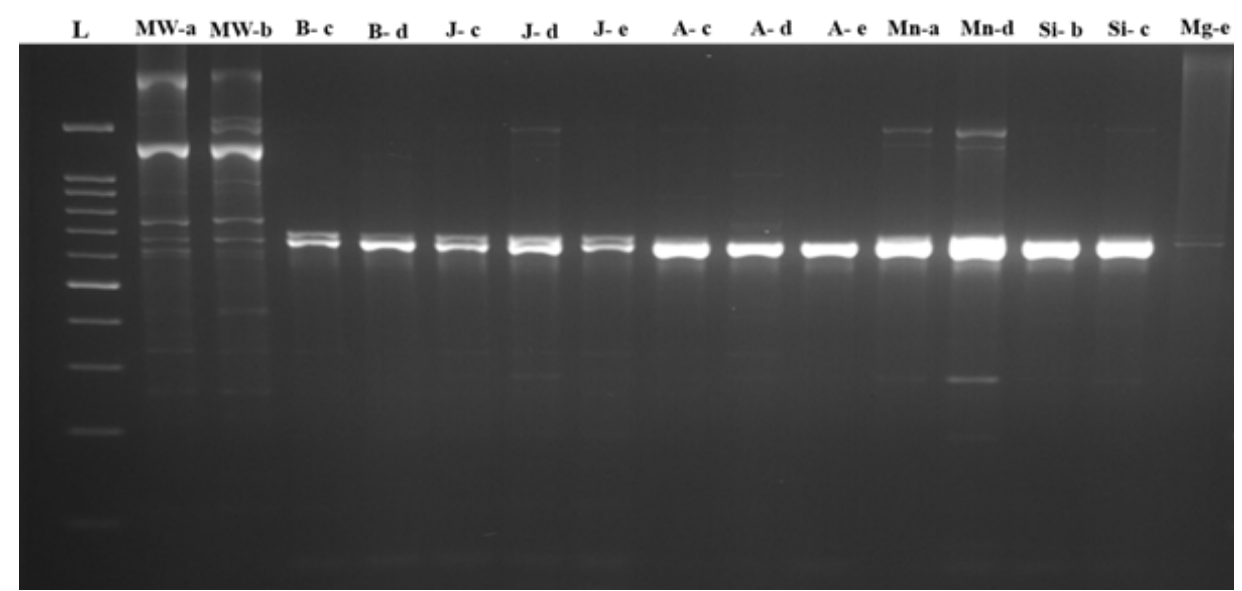

Figure 6: The ERIC profiling of 15 rhizobial strains. ERIC profile for 15 selected rhizobial strains performed using ERIC $1 \mathrm{R}$ and ERIC $2 \mathrm{R}$ primers. DNA banding patterns highly polymorphic which some bands prominent and observe in each strain. The similar banding pattern observes in MW-a and MW-b strains and j-c, J-b and B-c strains

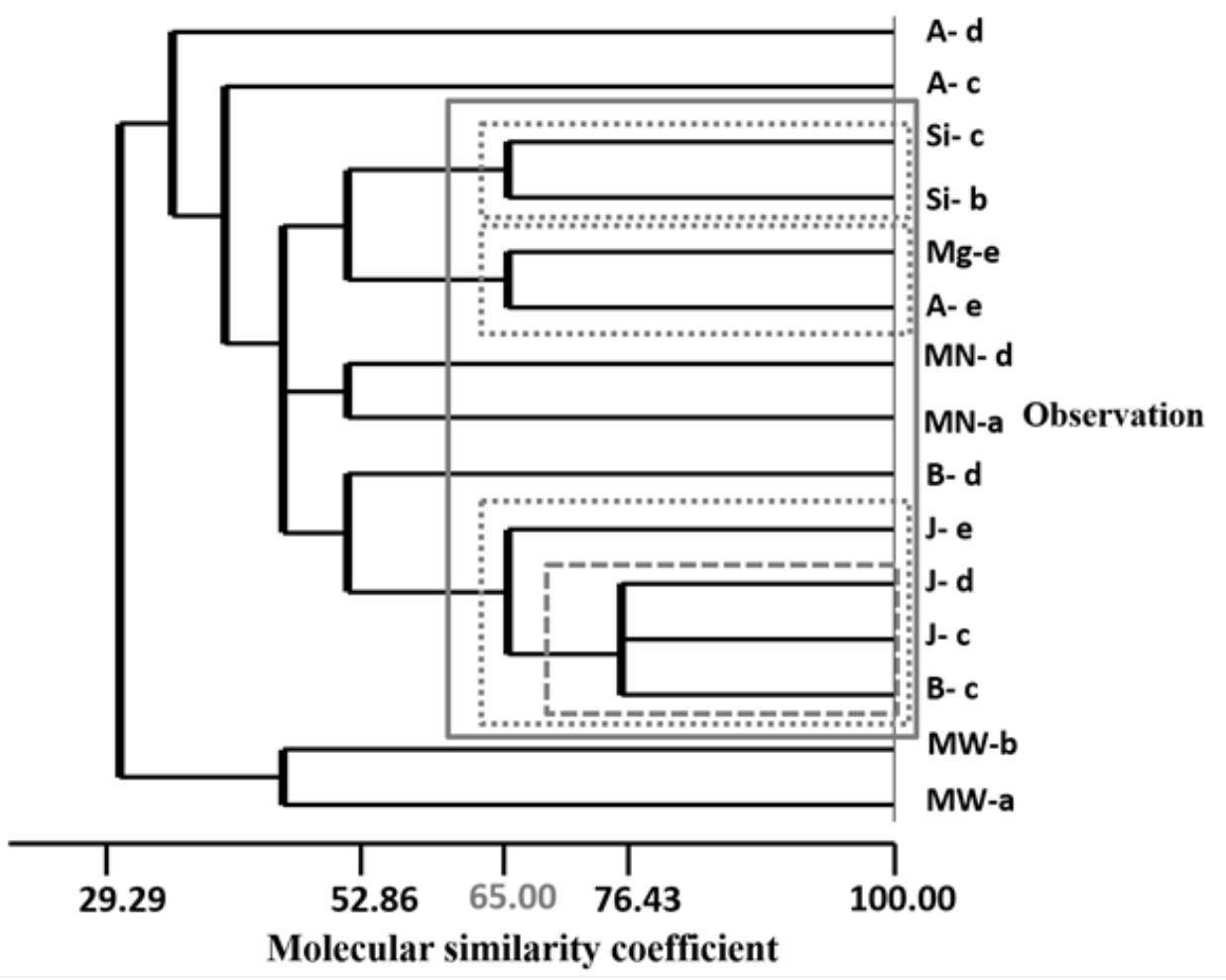

Figure 7: Dendrogram showing the genetic relationship between selected 15 rhizobial strains. The dendrogram was constructed by the complete linkage Euclidean distance method using the statistical software MINITAB 16.1.0. The J-c, J-d, and B-c strains cluster together at $75 \%$ molecular similarity coefficient while MW-a and MW-b belong to out-group cluster at $44 \%$ molecular similarity coefficient. The 15 strains belong to 10 clusters at $65 \%$ molecular similarity coefficient. 
distributed in this district and frequently used as a shade for crops, live fences, crop supporters, and green manure in rice fields, other cultivated lands, and home gardens. Usually, a large number of root nodules found in the lateral roots which are located near the surface soil. The rhizobial population showed optimum growth at temperatures $37^{\circ} \mathrm{C}$ and $38^{\circ} \mathrm{C}$ and at the highly aerobic conditions of the surface soil in Polonnaruwa district (Rathnayake et al., 2009). Most nodules collected from the seven sites had a spherical shape while some nodules in Medirigiriya, Moragaswewa, and Bakamuna locations had coralloid shape. Unlike other nodules, Monarathanna sampling site had elongated nodules that was inhabited by a heterogeneous population of rhizobia.

According to the results of $\mathrm{pH}$ tolerance, all samples have shown a higher growth at neutral $\mathrm{pH}$. Somasegaran and Hoben, (2012) stated that optimum growth of rhizobia is at the soil $\mathrm{pH}$ of 6.0-7.0. But some strains like MWa, B-d, J-a, J-b, A-c, A-d, MN-e, Si-e, and Mg-b have a higher tolerance to high alkaline $\mathrm{pH}$ as the varying soil pH from 5.7 to 7.1 in Polonnaruwa district could be the predominant cause (Rathnayake et al., 2009). Thus, the $\mathrm{pH}$ range of 3.0-9.0 selected to analyze the tolerance of rhizobial strains. Moreover, Degefu et al., (2018) have demonstrated that rhizobia nodulating pigeon pea could survive a broad $\mathrm{pH}$ range from $\mathrm{pH}$ 5.0- 11.0. The highly acidic $\mathrm{pH}$ (1.0 and 2.0) or highly alkaline $\mathrm{pH}(10.0-14.0)$ was not considered since such conditions do not exist in the natural soil of Sri Lanka. Hungriaa and Vargas, (2000) explained that the highly acidic soil $\mathrm{pH}$ severely affects the growth of rhizobial strains and its infection cycle during nodule formation. Hence, the results of the present study correlate with the above findings by showing less growth of rhizobial strains at acidic $\mathrm{pH}$ (3.0 and 4.0).

Due to the limited two short rainy seasons and high evaporation rate in Polonnaruwa district, the moisture content of the soil is reduced increasing drought stress. Generally, moisture deficiency decreases the growth of the plant and the root nodulation process. However, $G$. sepium that grew in the dry zone naturally has the ability to survive and distribute well under drought conditions. Thus, it leads to the enhancement of the symbiotic relationship with stress tolerant rhizobial strains and the nodulation process. Here, PEG was used in vitro to induce water stress in the culture medium. In the drought tolerant test, $570 \mathrm{~nm}$ was used to normalize the effect of added PEG. According to the results of drought stress, most strains like MWa, B-e, J-c, A-b, A-d, A-e, MN-a, MN-e, and Si-c, show a higher tolerance even at the highest PEG concentration $(0.40 \%)$. However, the moisture percentage in the soil of Polonnaruwa district ranged from $7.6 \%$ to $11.5 \%$ between March and April of 2018 (Unpublished data from Division of Soil science, Institute of Regional Agricultural Research and Development Center, Aralaganwila, 2018). Due to the adaptation of G. sepium for moisture deficiencies found in Polonnaruwa district, the inhabiting rhizobial strains also show tolerance for drought stress.

The salinity level of the dry zone soil is relatively higher than that of the wet zone. This is mainly due to the accumulation of high concentration of salt in the soil which occurs through high evaporation and irrigation of salt content water to cultivation (Lauchli and Epstein, 1990). Moreover, the growth of rhizobia and their symbiotic relationship are adversely affected by high salinity level. Thus, most rhizobial strains isolated from Polonnaruwa district show adaptation for high salinity levels. Although most strains show high tolerance at $1.0 \%$ and $1.5 \% \mathrm{NaCl}$ concentration, the growth of the isolates is reduced at high salt concentrations. The soil salinity in Polonnaruwa district is varying from 0.07 to $0.300 \mathrm{ds} / \mathrm{m}$ and this could be a major factor for moderate salinity conditions (Unpublished data from the Division of Soil science, Institute of Regional Agricultural Research and Development Center, Aralaganwila, 2018). Some strains like MW-c, B-d, A-a, MN-c, Si-d, Si-a, Si-c, and Mg-a show moderate tolerance $(>0.7000$ mean absorbance value) at $3.0 \%$ of $\mathrm{NaCl}$ concentration because $3.0 \%$ of tested salinity level gives $0.495 \mathrm{ds} / \mathrm{m}$ electron conductivity. Usually, the $R$. etli, and $R$. meliloti are highly tolerant to high salt concentration (Graham and Parker, 1964). Thus, the tested $\mathrm{NaCl}$ concentration ranging from $0.1 \%$ to 3.0 $\%$ is reliable as more than $3.0 \%$ of salinity level does not exist in the soil condition of Polonnaruwa district. The soil temperature in Polonnaruwa distinct is varying from $37^{\circ} \mathrm{C}$ to $38^{\circ} \mathrm{C}$ which causes water loss from the soil (Rathnayake et al., 2009). The high soil temperature can affect the plasmid deletion, chromosomal rearrangement, and survival of the rhizobial strains (Moawad and Beck, 1991). Thus, the high temperature negatively affects the growth of most strains as their best growth is shown at $25^{\circ} \mathrm{C}$ and 30 ${ }^{\circ} \mathrm{C}$. On the contrary, some strains such as MW-a, MW-b, B-d, B-e, A-c, A-d, MN-a, and Si-b show adaptations even at $45^{\circ} \mathrm{C}$.

The combination of physiological conditions was selected by considering the natural conditions in the Polonnaruwa district. The incubation temperature of $40{ }^{\circ} \mathrm{C}$ was selected because the soil temperature of the Polonnaruwa district is close to $40{ }^{\circ} \mathrm{C}$. Since the rhizobia shows optimum growth at $6.0-7.0$ range, the $\mathrm{pH} 6.8$ is used for combination conditions. The $3.0 \%$ of salt concentration and $0.40 \%$ of drought conditions were selected because the salinity level spontaneously increases with the increase of drought condition in the soil. Although, MW-a strain shows high growth for some individual conditions like $\mathrm{pH}$, temperature, and drought, the extreme salinity in the combination medium might have become a limiting factor for $\mathrm{MW}$-a strain as it has shown poor growth at $3.0 \% \mathrm{NaCl}$ concentration. Other selected strains are highly adapted to extreme conditions as they show a considerable tolerance for combined conditions while Si-b, Si-c, and Mg-e strains show high tolerance as expected. Stress factors such as extreme temperature, high salinity level and extreme $\mathrm{pH}$ lead to reduction of nodulation and thus low rate of nirogen fixation resulting in reduced crop yield. Thus, stress tolerant rhizobial strains can be used to as inoculants to improve biological nitrogen fixation in sustainable agricultural systems (Atieno and Lesueur, 2019).

The genetic diversity determined using the ERIC profiling showed high polymorphism among the 15 
selected strains. The MW-a and MW-b strains belong to an out-group cluster indicating their higher relatedness in the dendrogram analysis. The three strains of Jayanthipura, two strains of Monarathanna and two strains of Sinhapura separately cluster together by representing their geographical relationship. And the relationship among Sinhapura strains was also confirmed in the combined physiological condition. But there is no relationship between the sampling site and rhizobial strains. Nawanjana and Rajapakse, (2018) have reported that there is a high genetic diversity of rhizobia in G. sepium from Ampara district, Sri Lanka. Similarly, the present study provides further evidence for the fact that a diverse group of stress tolerant rhizobia inhabits G. sepium in dry zone soils, Sri Lanka. Rhizobial inoculants both single strain and multistrain have the capability of replacing urea application to black gram, soybean, and mung bean crop cultivations in Sri Lanka (Hettiarachchi, 2015). Therefore there is a potential to use the stress tolerant rhizobial isolates identified in this study to cross inoculate crop legumes such as cowpea, mung bean, black gram which are important grain legumes in rain fed farming systems in dry and intermediate zones of Sri Lanka including the districts of Polonnaruwa, Anuradhapura, and Puttalam.

\section{CONCLUSIONS}

The 35 samples of rhizobia isolated from root nodules of G. sepium in Polonnaruwa district showed substantial tolerance to a wide range of $\mathrm{pH}$, salinity, drought, and temperature conditions. Among the selected 15 rhizobial strains, 14 strains have great tolerance except for MW-a strain. All 15 isolates exhibit high adaptations towards the considered extreme physiological conditions similar to their host, G. sepium in Polonnaruwa district. According to the dendrogram analysis prepared using ERIC-PCR fingerprinting, the selected 15 rhizobial strains have a wide genetic diversity.

\section{ACKNOWLEDGEMENTS}

Division of Soil Science, Institute of Regional Agricultural Research and Development Center, Aralaganwila.

\section{DECLARATION OF CONFLICT OF INTEREST}

The Authors declare that there is no conflict of interest.

\section{REFERENCES}

Atieno, M. and Lesueur, D. (2019). Opportunities for improved legume inoculants: enhanced stress tolerance of rhizobia and benefits to agroecosystems. Symbiosis 77(3): 191-205.

Brockwell, J., Bottomley, P.J. and Thies, J.E. (1995). Manipulation of rhizobia microflora for improving legume productivity and soil fertility: a critical assessment. Plant and Soil 174(1-2): 143-180.

Brockwell, J., Searle, S.D., Jeavons, A.C. and Waayers, M. (2005). Nitrogen fixation in acacias: an untapped resource for sustainable plantations, farm forestry, and land reclamation. Australian Centre for International Agricultural Research, Canberra, Pp.2-132.

Degefu, T., Wolde-meskel, E., Adem, M., Fikre, A., Amede,
T. and Ojiewo, C. O. (2018). Morpho-physiological diversity of rhizobia nodulating pigeon pea (Cajanus cajan L. Mill sp.) growing in Ethiopia. African Journal of Biotechnology, 17(6): 167-177.

Franche, C., Lindstrom, K. and Elmerich, C. (2009). Nitrogen-fixing bacteria associated with leguminous and non-leguminous plants. Plant and Soil 321(1-2): 35-59.

Graham, P.H. (1992). Stress tolerance in Rhizobium and Bradyrhizobium and nodulation under adverse soil conditions. Canadian Journal of Microbiology 38(6): 475-484.

Graham, P.H. and Parker, C.A. (1964). Diagnostic features in the characterization of the root-nodule bacteria of legumes. Plant and soil 20: 383-396.

Gunathilake, H.A.J., Joseph, P.G., Wickremasinghe, H. and Peiris, T.S.G. (2005). Sustainable biomass production in Sri Lanka and possibilities for agroforestry intervention. Proceedings of International Conference on the Issues for Sustainable use of Biomass Resources for Energy, Colombo, Pp.15-18.

Hettiarachchi, C.S. (2015). Rhizobiology of some crop legumes in Sri Lanka for production of rhizobial inoculants. Ph.D. Thesis, Postgraduate Institute of Science, University of Peradeniya.

Hettiarachchi, C.S., Abhayasekera, C.L., Rajapakse, S., Kulasooriya, S.A. and Kumar, P.S. (2013a). Screening of stress tolerant rhizobial isolates from wild legumes growing in the southern coastal region of Sri Lanka. Proceeding in $33^{\text {rd }}$ Annual Research Sessions, Institute of Biology, Sri Lanka, P.49.

Hettiarachchi, C.S., Kumar, P.S., Abhayasekra, C.L., Rajapakse, S. and Kulasooriya, S.A. (2013b). Development of rhizobial inoculants which can reduce chemical fertilizer use in Glycine max (soybean) cultivation in Sri Lanka. Proceeding of $18^{\text {th }}$ International Congress on Nitrogen Fixation, Miyazaki, Japan, P.140.

Hungriaa, M. and Vargas, M.A.T. (2000). Environmental factors affecting N2 fixation in grain legumes in the tropics, with an emphasis on Brazil. Field Crops Research 65(2-3): 151-164.

Jayasundara, H.P.S., Dennett, M.D. and Sangakkara, U.R. (1997). Biological nitrogen fixation in Gliricidia sepium and Leucaena leucocephala and transfer of fixed nitrogen to an associated grass. Tropical Grasslands 31: 529-537.

Kulasooriya, S.A., Gamini S. and Ekanayake, E.M.H.G.S. (2017). Soil Microbial Diversity and Its Utilization in Agriculture in Sri Lanka. In: , J. K. Patra, N.V. Chethala and G. Das (Eds.) Microbial Biotechnology, Springer Nature, Singapore Pte Ltd. https://doi.org/10.1007/978981-10-6847-8 9.

Lauchli, A. and Epstein, E. (1990). Plant responses to saline and sodic conditions. Agricultural Salinity Assessment and Management 71: 113-137.

Liyanage, L.V.K., Jayasundara, H.P.S. and Gunesekera, T.G.L.G. (1988). Potential for use of nitrogen-fixing tree legumes in small coconut holding in Sri Lanka. Proceedings of an 11. International workshop on the Multipurpose Tree Species for Small Farm Use, Pattaya, Thailand, Pp. 251-253. 
Liyanage, M.D.S., Danso, S.K.A. and Jayasundara, H.P.S. (1994). Biological nitrogen fixation in four Gliricidia sepium genotypes. Plant and Soil 161(2): 267-274.

Martinez-Romero, E., Segovia, L., Mercante, F.M., Franco, A.A., Graham, P. and Pardo, M.A. (1991). Rhizobium tropici, a novel species nodulating Phaseolus vulgaris L. beans and Leucaena sp. trees. International Journal of Systematic and Evolutionary Microbiology 41(3): 417-426.

Moawad, H. and Beck, D.P. (1991). Some characteristics of Rhizobium leguminosarum isolates from uninoculated field-grown lentil. Soil Biology and Biochemistry 23(10): 933-937.

Nawanjana, P.W.I. and Rajapakse, S. (2018). Physiological Characterization and Genetic Diversity Assessment of the rhizobial Populations Inhabiting Gliricidia sepium in selected Locations of Ampara District, Sri Lanka. Journal of Agricultural Sciences-Sri Lanka 14(1): 34-48.

Peoples, M.B. and Craswell, E.T. (1992). Biological nitrogen fixation: investments, expectations and actual contributions to agriculture. Plant and soil 141(1-2): 13-39.

Peter, J., Young, W. and Haukka, K.E. (1996). Diversity and phylogeny of rhizobia. New Phytologist 133(1): 87-94.

Rathnayake, W.M.U.K., Nayanake, V.G.D., Sirisena, D.N., Mapa, R.B., Atapattu, A.M.K.B. and Wickramasinghe, W.M.D.B. (2009). Variability of major soil chemical properties and their suitability for rice cultivation at pulasthigama farmer fields in Sri Lanka.

Sawada, H., Kuykendall, L.D. and Young, J.M. (2003).
Changing concepts in the systematics of bacterial nitrogen-fixing legume symbionts. The Journal of General and Applied Microbiology 49(3): 155-179.

Somasegaran, P. and Hoben, H. J. (2012). Handbook for Rhizobia: methods in legume-Rhizobium technology. Springer Science \& Business Media publishing, Germany.

Udagedara, M.D. and Sugirtharan, M. (2018). Status of micro irrigation systems adopted for vegetable cultivation in Polonnaruwa district, Sri Lanka. Journal of Agricultural Sciences 11.

Ulluwishewa, R. (1993). An environmental profile of the Polonnaruwa district. Central Environment Authority printers, Maligawatte New Town, Colombo 10, Sri Lanka, P.48.

Versalovic, J., Koeuth, T. and Lupski, R. (1991). Distribution of repetitive DNA sequences in eubacteria and application to fingerprinting of bacterial genomes. Nucleic Acids Research 19(24): 6823-6831.

Zahran, H.H. (2001). Rhizobia from wild legumes: diversity, taxonomy, ecology, nitrogen fixation and biotechnology. Journal of Biotechnology 91(2-3): 143153. 